In Conversation with
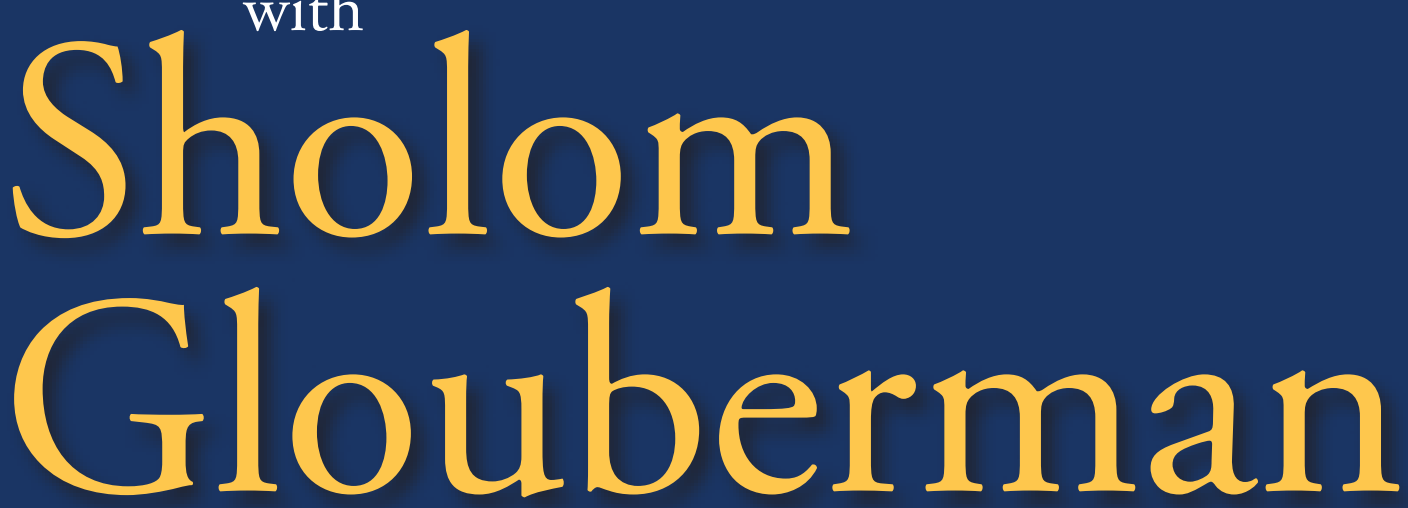

\title{
Ken Tremblay
}

W

ith credentials from McGill and Cornell universities and a diverse career as philosopher-in-residence at the Baycrest Centre for Geriatric Care in Toronto, fellow at the King's Fund in London and many engagements as policy advisor and consultant on both sides of the Atlantic, Sholom Glouberman, PhD, has contributed to Canada's finest healthcare organizations. When a need to use the healthcare system presented itself in 2005, Glouberman was not your average patient. In his book, My Operation: A Health Insider Becomes a Patient (2010), he chronicled his take on the gaps between the perceptions of patients and providers. That experience gave rise to a new chapter in his career as founder and president of the Patients' Association of Canada (PAC). Formed in 2007 and governed by patients themselves, PAC - now renamed Patients Canada - has a mandate is to give patients a voice (make your experience count) and to empower Canada's patients as policy makers, disease organizations, researchers, professions and providers address Canada's complex healthcare agenda. Glouberman shared his thoughts with Ken Tremblay over the summer.

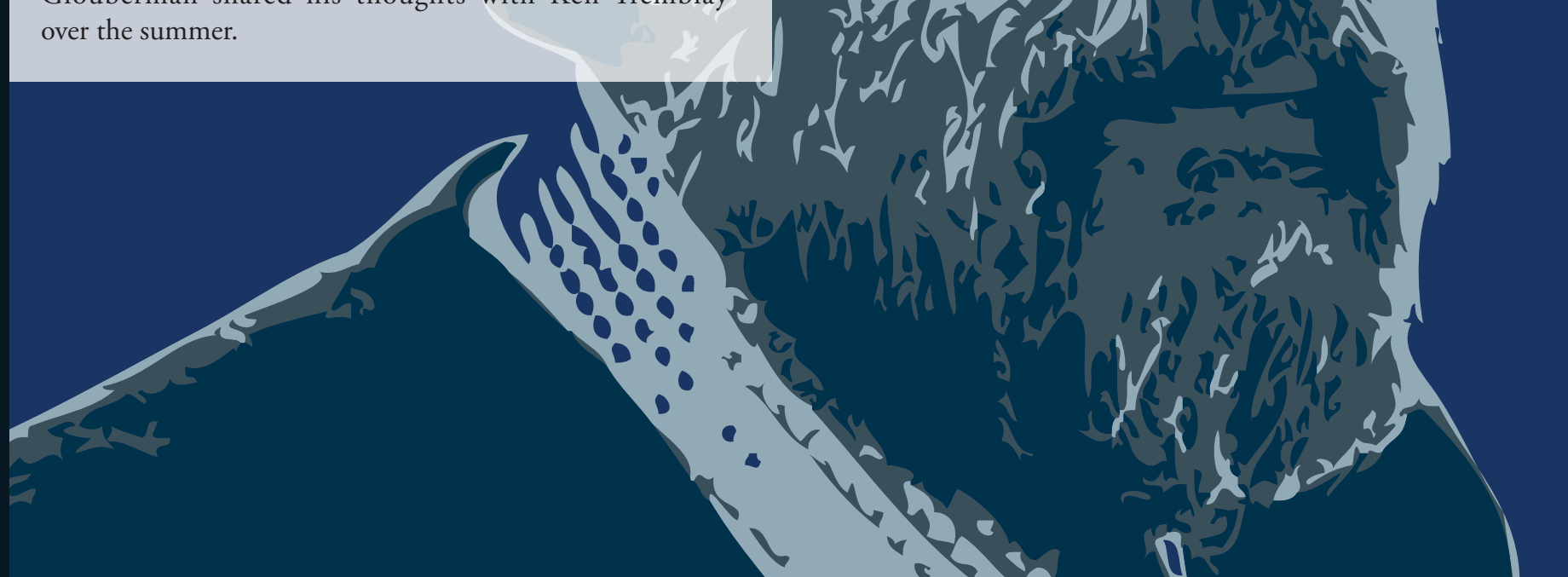


HO: Why did you create PAC? What was the gap?

SG: We started the Patients' Association because I had an operation and became a patient. After that experience, I managed to get appointed to a hospital committee. Knowing a lot having worked in hospitals, I realized that I couldn't come on [this journey] alone; so, I got a bunch of people to join me.

\section{HO: What have been the challenges of creating a} new national voice for patients when much of the delivery, policy and funding activities emanate from and rest with the provinces?

SG: Patients do not experience a national organization; rather, they experience tremendous disruption in their lives. There are differences among various organizations inside one province and between services covered and provided across others. That [inconsistency] certainly is one of the issues for patients. That we have a national perspective is really critical because many problems have to do with the variation in which health is delivered across the country.

\section{HO: What have been your observations about} the variations in the outcomes and experiences Canadians have with their healthcare system? What differences were most remarkable?

SG: The most remarkable differences across the country are that coverage and the ground rules are completely different. For example, some services or procedures covered in Saskatchewan aren't covered in Ontario. Similarly, you find that the way in which you complain about services or seek services in one province is very different than in the next. It's really quite interesting.

HQ: How have your perspectives about the healthcare system been changed through the work you do with PAC?

SG: The thing I learned most is that the patient perspective and experience in healthcare are very, very different from that [assumed] by providers. It's worth hearing that: healthcare providers need to understand how patients feel about what's being provided to them.

HQ: Given the diversity of patients, their conditions, experiences and geography, how do you find consensus or determine the priorities needed for an organization like PAC?

SG: What we do in the Patients' Association is listen to everybody's stories. We have a group of people who spend a lot of time thinking about what the stories mean and what things in the system should change in order to improve both the patient experience and that of providers. We're interested in improving the healthcare system, and we're interested in working with providers to do that. We don't see ourselves as an isolated group arguing only for the patient perspective.

HO: What would be your vision as to how PAC's efforts would shape patient experiences and clinical outcomes? What would be the difference from those of today?

SG: The most important thing to note about the Canadian healthcare system is that it is focused on hospitals and doctors; its history was built around hospital insurance and coverage for doctor services. This makes the system unbalanced: left out are people with chronic conditions, largely healthy, who live in the community. Services for them and to them should be close and in the community; people shouldn't have to travel many miles to go see a specialist, and people should not have to wait for an acute episode in order to be treated.

\section{Medical schools need to recognize and acknowledge that the most important place for a patient with chronic conditions is in the community.}

\section{HQ: PAC is arguably the ultimate patient-} centred organization, in its objects, membership, governance, operations and advocacy. How has that shaped the organization's approach to policy makers, providers and the professions?

SG: We've been working with policy makers, providers and the professions in order to determine what can be changed easily. We see ourselves working within the system to bring a new perspective to the system rather than fighting against [it]. Probably that's been the basis of much of our success. Our first project, which was really interesting (in fact, it happened in Peterborough), was to join with the Ontario Medical Association to develop a program called the Patients' Choice Awards. With the Patients' Choice Awards, patients nominate doctors who are especially patient friendly, and a patient jury selects the recipients using its own criteria. We've done this successfully across seven different localities in Ontario; the awards really shape the modelling of a good [patient-friendly] practice.

HQ: When we say that we want to empower patients as we engage them in the planning, delivery and evaluation of health services, how has that goal shaped grassroots participation in PAC?

SG: Patients have been without power or without a voice for so long that simply giving them a place at the table is a big change. The way in which that has happened most is where hospitals have brought patients on as patient and family advisors. These 
people sit on committees; they help hire new staff. In Thunder Bay, for example, there are two patient and family advisors who sit on [that hospital's] Executive Council. They are deeply enmeshed in the organization, and their job is to bring the patient perspective to decisions, policy discussions and service design. It makes a very big difference.

\section{HO: What have been the early wins for PAC and what, if any, have been your setbacks?}

SG: There have been setbacks. The biggest setback: in the healthcare system, patients are considered to be a free good. Much of our struggle has been to find enough funding to survive, to have office support staff and to do things like sponsoring conferences. We're overcoming that, but money is always a problem for new organizations, especially for organizations built around patients.

\section{HO: Some provinces are making great strides in deploying e-health strategies geared to improving the patient journey and experience. Are there any shining examples you want to highlight as particularly central to the goals of PAC?}

SG: There are many examples. Saskatchewan has worked very hard to bring the patient perspective to healthcare and has done a terrific job. Alberta Health has an office focused on patient engagement, and their work is interesting. British Columbia has groups of people trained to take on really important roles in the system and in different ways. Ontario's Health Links Project is very conscious of the patient role, and the PATH [Partners Advancing Transitions in Healthcare] project in Northumberland is a model for how patients can have a very powerful and interesting voice in redesigning healthcare. Nova Scotia has significant numbers of people who are trained, serving in patient roles in the system. I see [this activity] happening all over the country and happening more and more quickly.

HQ: How does PAC deal with the social determinants of health or the notion of that we need more personal responsibility for health status? As we promote partnerships for healthcare delivery, what is the role of PAC and its members?

SG: We believe that strengthening the patient voice and making patients feel as if they can take on more responsibilities in healthcare are absolutely critical. That also goes for caring for themselves. The social determinants of health have to do with those things that we can do on our own. They also relate to things at the social level, not necessarily only healthcare.

For example, one of the comparators we looked at is Canada's food strategy: Canada's food strategy would be very different if consumers/patients began to have a voice in it. Developing people's voices should spread through society. We are a relatively weak society in terms of a consumer voice. Healthcare is a great place where we can strengthen and spread that [participation] through society.

HO: How do we teach current and future generations of healthcare professionals about the empowered patient and the need to reduce the paternalism they find so disconcerting? For example, what key message would you have for clinicians attending grand rounds?

SG: I did grand rounds at St. Mike's. It was very interesting to see how different people reacted to what I was sharing, shedding new light on the work that they do. The patient perspective on clinical practice can be enlightening, and involving patients more can be very important [for caregivers].

Your question is a much more important than that. One recent change is that the McGill University Medical School decided it was going to produce more family doctors and fewer specialists. We need much more community-based medical care than specialists [for chronic conditions]. We need many more services in the community; this decision by McGill represents a very important step in that direction.

Medical schools need to recognize and acknowledge that the most important place for a patient with chronic conditions is in the community. We need to avert acute episodes of chronic diseases in hospitals; it's not like acute infectious diseases in the old days.

\section{HO: Do you see more patients participating in the curriculum?}

SG: Sure, and it's already starting to happen. We need sessions in the curriculum that bring the patient perspective to doctors so that they understand better whom they are treating.

\section{The thing I learned most is that the patient perspective and experience in healthcare are very, very different from that [assumed] by providers.}

\section{HO: Any sense as to how the "system" [providers, professions, policy makers] has responded or embraced the messages you bring from PAC?}

SG: Most people are really happy to have us there. The vast majority of people recognize that the insights we bring can be very useful as well as help them do their job better. Some people believe that healthcare should continue to be an expertbased system with patients having a minimal role. For the most part, people are ready to have us [at the table]. I have been pleased that we haven't had as much pushback as we thought we would. 
HQ: As a philosopher and insider who became a patient and advocate, what is your message to fellow patients? To readers?

SG: To fellow patients: This is a chance for you to participate in the healthcare system. One of the trends happening these days is the role of patient navigator; I think patients want to change the system so that we don't need navigators, so that the system is self-explanatory and pretty transparent. In short, you can get around the system because the system is clear, not because you need or have a guide.
To readers: We're providing stuff that will help them do their jobs. For example, we've just set up a series of learning sets for people who are leading patient engagement in the Health Links [Project]. This will help them to better engage patients and their voices within the system.

\section{HO: Thank you.}

\section{Reference}

Glouberman, S. 2010. My Operation: A Health Insider Becomes a Patient. Toronto, ON: Health and Everything Publications.

\section{WAYS \& MEANS A leadership conference about tools, strategies and to make Health Links work partnerships to enable change for better care and affordable care - May 15, 2013}

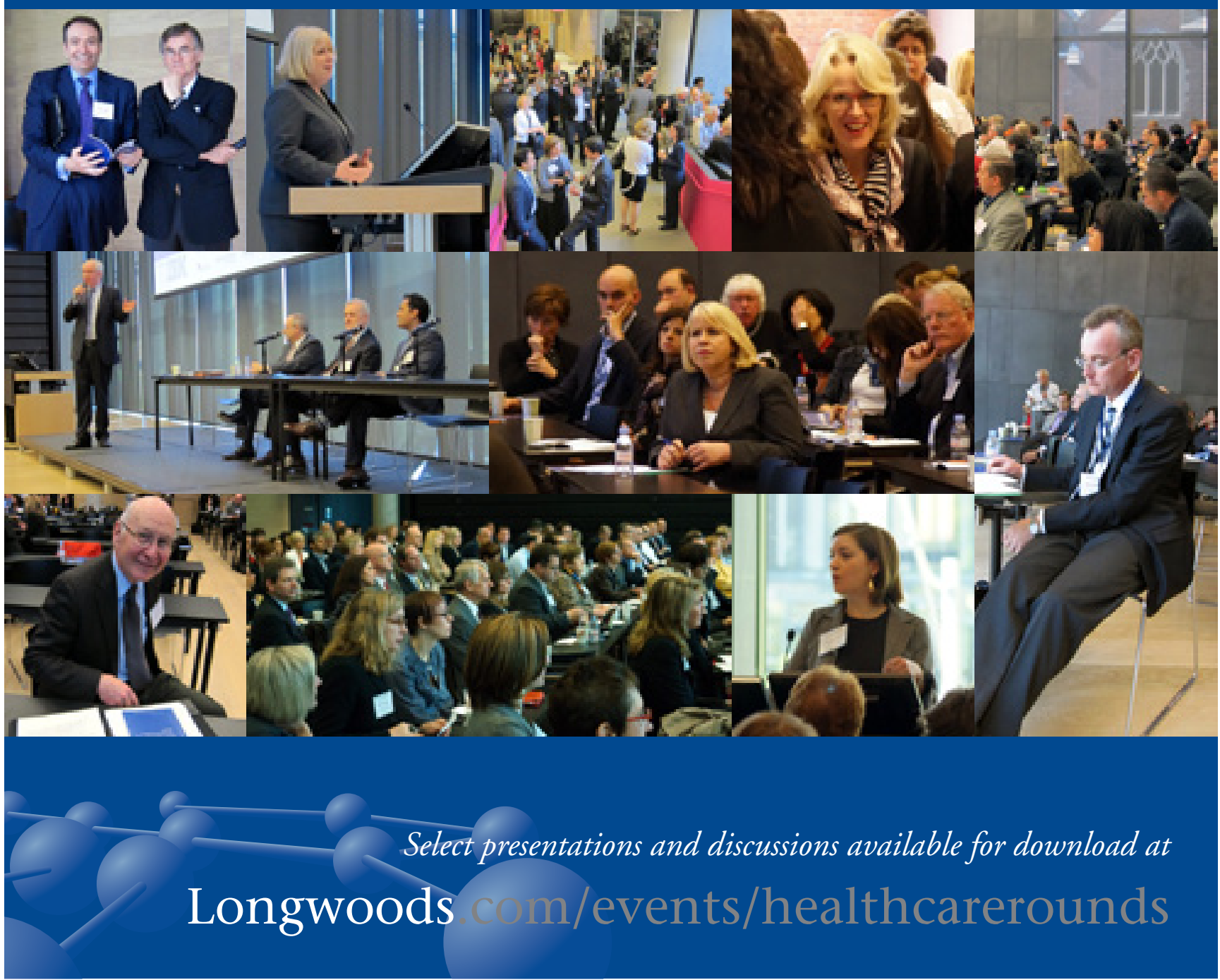

